\title{
Estimasi usia prajurit TNI AL berdasarkan Tooth Coronal Indexpada digital radiograf panoramik
}

\author{
Reni Indah Yolanti ${ }^{*}$, Suhardjo Sitam² (iD, Ganesha Wandawa ${ }^{3}$, Farina Pramanik²
}

\begin{abstract}
Objectives: The purpose was to determine the estimated chronological age difference between Indonesian Navy soldiers (TNI-AL) and dental age based on the Tooth Coronal Index on panoramic digital radiographs, which are used as antemortem data for the purposes of identifying Indonesian Navy soldiers if they have an accident while on duty or on the battlefield where only tooth remains.
\end{abstract}

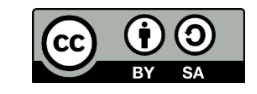

${ }^{1}$ Kementerian Pertahanan, Klinik Pratama Kemhan, Jakarta, Indonesia

${ }^{2}$ Departemen Radiologi Kedokteran Gigi, Fakultas Kedokteran Gigi, Universitas Padjadjaran, Bandung, Indonesia 40132

${ }^{3}$ Lembaga Kedokteran Gigi TNI AL R.E. Martadinata, Jakarta, Indonesia

*Correspondence to:

Reni Indah Yolanti

凶drgreiniyolanti@gmail.com

Received on: September 2020 Revised on: November 2020 Accepted on: December 2020
Material and Methods: The method used was a cross-sectional observational survey with the sampling technique using purposive sampling. This study used 86 digital panoramic radiographs of Indonesian Navy soldiers who were assigned abroad from 2015-2017 at the Dental Radiology Installation of Ladokgi TNI AL R.E. Martadinata. The teeth measured were mandibular first molars with the Tooth Coronal Index (TCI) method, which is a method of estimating age based on secondary dentin deposition and tooth pulp size on dental radiographs.

Results: The results of the chronological age difference with the dental age of Indonesian Navy soldiers using the Tooth Coronal Index (TCI) method on a panoramic digital radiograph performed on mandibular first molars were an average of 6.3 years.

Conclusion: The dental age of Navy soldier is higher than chronological age.

Keywords: Navy soldier, digital archive of panoramic radiographs, method of Tooth Coronal Index (TCI)

Cite this article: Yolanti RI, Sitam S, Wandawa G, Pramanik F. Estimasi usia prajurit TNI AL berdasarkan Tooth Coronal Index pada digital radiograf panoramik. Jurnal Radiologi Dentomaksilofasial Indonesia 2020;4(3)61-6. https:// doi.org/10.32793/jrdi.v4i3.591

\section{PENDAHULUAN}

Tentara Nasional Indonesia, yang selanjutnya disingkat TNI adalah alat negara yang bertugas mempertahankan, melindungi, dan memelihara keutuhan dan menegakkan kedaulatan negara. ${ }^{1}$ Tugas sebagai TNI sangat berat karena harus siaga 24 jam dalam sehari, 7 hari dalam seminggu dan 365 hari dalam setahun, ${ }^{2}$ untuk itu salah faktor yang mendukung profesionalisme TNI yaitu menjaga kesehatan fisik meupun kesehatan jiwa. Kesehatan prajurit yang prima, mutlak diperlukan agar mampu mengemban tugas berat sebagai komponen utama pertahanan negara. Salah satu unsur dari TNI adalah Tentara Nasional Indonesia Angkatan Laut (TNI AL). Prajurit TNI AL mempunyai tugas dalam menjaga kedaulatan Negara Kesatuan Republik Indonesia (NKRI) maka para prajurit TNI AL harus siap ditempatkan dalam bertugas dimanapun dan dikirim keluar negeri sebagai pasukan perdamaian ataupun operasi militer di laut, sehingga mempunyai resiko yang sangat besar mengalami kecelakaan di medan perang perang ataupun di daerah operasional. Apabila terjadi kecelakaan saat bertugas pada prajurit TNI AL dan tidak dapat dikenali lagi dan hanya bagian gigi yang tersisa, maka diperlukan proses identifikasi melalui gigi. Untuk itu, diperlukan pemeriksaan kesehatan gigi dan mulut pada prajurit TNI AL salah satunya adalah pemeriksaan radiologi yaitu panoramik.

Radiografi panoramik merupakan teknik radiografi ekstra oral yang dapat memperlihatkan rahang atas dan bawah sekaligus, serta struktur anatomi yang berdekatan dalam satu film. ${ }^{3}$ Panoramik radiograf ini digunakan sebagai data antemortem prajurit TNI AL, untuk kepentingan identifikasi pada prajurit TNI AL dalam mengestimasi usia dilihat dari gambaran gigi pada radiograf panoramik apabila prajurit mengalami korban kecelakaan saat bertugas ataupun di medan perang yang mengakibatkan tidak dapat dikenali lagi dan hanya bagian gigi yang tersisa. Perbandingan data antemortem dan postmortem melalui gigi menggunakan radiograf untuk kepentingan identifikasi dinilai akurat dan terpercaya. ${ }^{4}$ Estimasi usia merupakan hal penting dalam ilmu forensik odontologi untuk menentukan identitas manusia oleh karena dari berbagai bagian tubuh yang digunakan dalam estimasi umur, gigi paling tidak terpengaruh oleh proses taphonomic. Usia merupakan salah satu faktor penting dalam menentukan identitas seseorang. ${ }^{5}$ Usia dapat diperkirakan dengan cara yang berbeda dengan menggunakan usia kronologis, usia skeletal dan usia 
dental. ${ }^{6}$ Usia kronologis adalah usia aktual pada tiap individu. ${ }^{7}$ Usia dental dapat dilihat dan ditentukan melalui perubahan pekembangan gigi dan perubahan degeneratif pada gigi. Pulpa pada gigi dapat digunakan sebagai indikator dalam penentuan usia berdasarkan ukurannya karena seiring bertambahnya usia maka terjadi deposis dentin sekunder, oleh karena terjadi terus menerus maka dapat digunakan sebagai parameter estimas usia diatas 25 tahun. $^{8}$

Metode yang digunakan untuk menentukan usia gigi yaitu metode klinis, histologis, biokimiawi, dan radiologis. ${ }^{9}$ Metode radiografi merupakan metode yang mempunyai efek samping minimal terhadap estimasi usia diantara semua metode yang digunakan. ${ }^{10}$ Metode prakiraan usia melalui gigi menggunakan metode radiografi, seperti dilihat dari tahap kalsifikasi gigi dari metode scoring metode prakiraan usia dengan mengetahui perkembangan molar ketiga, dan morfologi gig yaitu mengestimasi prakiraan usia dengan metode Tooth Coronal Index (TCl). ${ }^{11}$ Metode Tooth Coronal Index ( $\mathrm{TCl})$ adalah metode estimasi usia berdasarkan deposisi dentin sekunder dan ukuran rongga pulpa gigi pada radiograf gigi. ${ }^{7}$ Penelitian tentang estimasi usia mellaui perbedaan usia kronologis dan usia dental menggunakan metode pengukuran Tooth Coronal Index (TCl) metode Benindra telah dilakukan pada Suku Banjar menggunakan radiograf periapikal dan didapatkan selisih rerata usia kronologis dan prakiraan usia lakilaki sebesar 0,4 tahun, sedangkan pada kelompok perempuan Suku banjar sebesar 0,47 tahun. Nila Tooth Coronal Index (TCl) semakin menurun dengan meningkatnya usia. ${ }^{18}$ Estimasi usia menggunakan Tooth Coronal Index (TCl) juga dilakukan pada populasi Mesir dan didapatkan selisih usia kronologis dengan usia dental pada laki-laki dan perempuan sebesar 0,136-0,170 tahun. Nilai Tooth Croronal Index (TCl) semakin menurun dengan bertambahnya usia. ${ }^{19}$ Penelitian tentang estimasi usia menggunakan pengukuran metode Tooth Coronal Index $(\mathrm{TCl})$ belum pernah dilakukan pada prajurit TNI AL.

Estimasi usia pada prajurit TNI AL untuk mendapatkan usia dental melalui radiograf panoramik dengan metode pengukuran Tooth Coronal Index $(\mathrm{TCl})$ dapat dilakukan apabila prajurit mengalami kecelakaan dalam bertugas dan bagian yang tersisa hanya gigi serta tidak diketahui usia kronologis dari prajurit. Metode pengukuran Tooth
Coronal Index (TCl) ini dapat dilakukan pada gigi premolar pertama rahang bawah dan gigi molar pertama rahang bawah atau hanya salah satu saja karena pada gambaran ruang pulpa gigi rahang bawah pada radiograf panoramik lebih jelas terlihat daripada rahang atas. Estimasi usia menggunakan metode Tooth Coronal Index $(\mathrm{TCl})$ pada radiografi panoramik adalah salah satu metode yang paling sederhana, andal, dan hemat biaya. ${ }^{12}$ Berdasarkan penjelasan diatas, peneliti ingin menganalisa estimasi usia dengan pengukuran Tooth Coronal Index (TCl) pada arsip radiograf panoramik prajurit TNI AL.

\section{BAHAN DAN METODE}

Jenis penelitian yang digunakan adalah metode survey deskriptif sederhana. Populasi pada penelitian ini adalah arsip digital radiograf panoramik prajurit TNI AL yang ditugaskan ke luar negeri di Instalasi Radiologi Kedokteran Gigi Ladokgi TNI AL R.E. Martadinata dari tahun 20152017. Sampel yang digunakan dalam penelitian in adalah sebanyak 86 buah arsip digital radiograf panoramik dari prajurit TNI AL yang ditugaskan ke luar negeri di Instalasi Radiologi Kedokteran Gigi Ladokgi TNI AL R.E. Martadinata.

Teknik pengumpulan data dengan mengambil arsip digital radiograf panoramik dari tahun 2015 2017 pada prajurit TNI AL yang ditugaskan ke luar negeri kemudian disimpan kedalam external hardisk. Langkah-langkah yang dilakukan yaitu mengambil data berupa arsip digital radiograf panoramik dari prajurit yang ditugaskan ke luar negeri dari tahun 2015-2017 di Instalasi Radiolog Kedokteran Gigi Ladokgi, seleksi arsip digital radiograf panoramik berdasarkan kriteria inklusi dan eksklusi, metode Tooth Coronal Index (TCl) yang diukur ada 2 bagian yaitu yang pertama adalah tinggi mahkota/Length of the Crown $(\mathrm{CL})$ dari Cemento Enamel Junction (CEJ) sampai ujung cusp mahkota tertinggi secara vertikal, kemudian yang kedua adalah tinggi tanduk pulpa/Corona Pulp Cavity Height $(\mathrm{CPCH})$ yang diukur mulai dari Cemento Enamel Junction (CEJ) sampai ke ujung tanduk pulpa tertinggi secara vertikal dengan satuan ukuran dalam milimeter.

Instrumen yang digunakan yaitu dengan IC Measure software dengan memilih menu device kemudian import selanjutnya buka radiograf

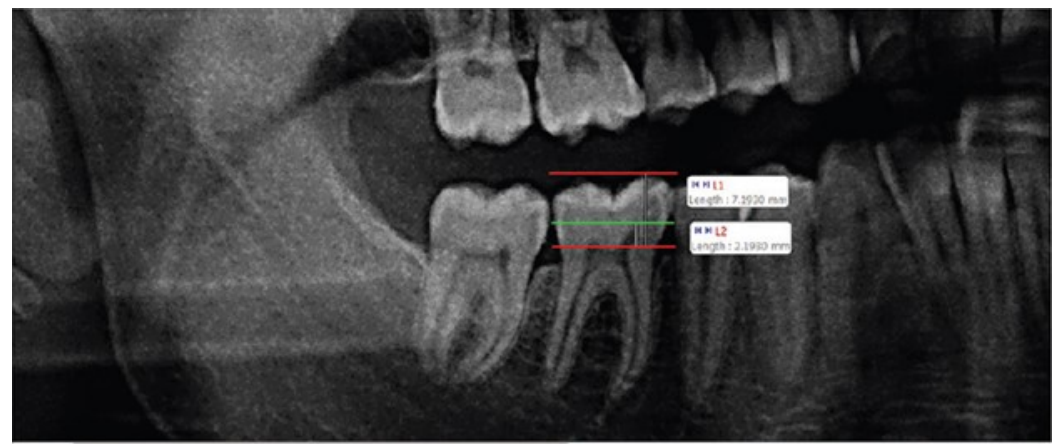

Gambar 1. Pengukuran TCl ${ }^{22}$ 


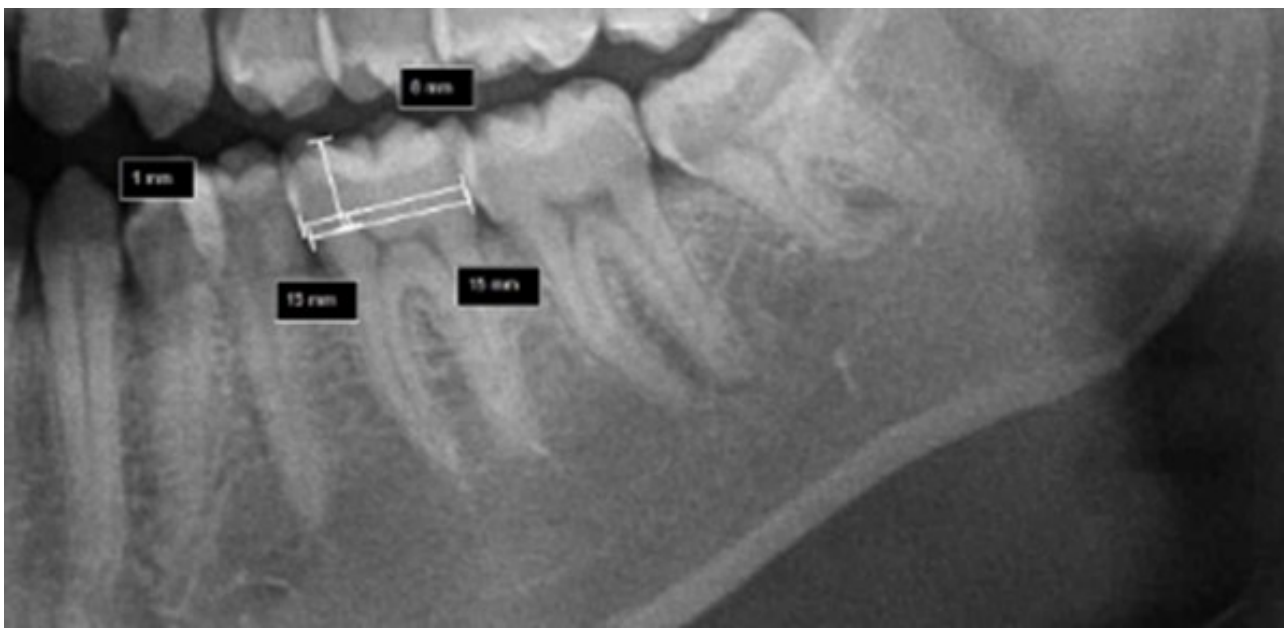

Gambar 2. Pengukuran TCI dengan IC Measure Software

panoramik dalam format jpeg, klik pada gigi yang akan diukur, tarik garis secara horizontal pada tanduk pulpa yang tertinggi, ukur tinggi tanduk pulpa yang tertinggi tarik garis secara vertikal, dan tarik garis secara vertikal dari CEJ ke cusp tertinggi pada mahkota, setelah itu akan didapat hasil pengukuran panjang ukuran dari CEJ ke tinggi tanduk pulpa tertinggi/Coronal Pulp Cavity Height (CPCH) dan dari CEJ ke cusp tertinggi mahkota/ Length of the Crown (CL) dalam satuan milimeter, hasil pengukuran dimasukkan ke dalam rumus Tooth Coronal Index (TCl). Rumus dari Tooth Coronal Index (TCl) adalah :

$$
\mathrm{TCI}=\frac{\mathrm{CPCH} \times 100}{\mathrm{CL}}
$$

Dari hasil Tooth Coronal Index $(\mathrm{TCl})$ kemudian di regresikan ke rumus persamaan untuk mendapatkan hasil nilai usia dental berupa angka. Setelah didapatkan hasil usia dental, kemudian analisis data, hasil penelitian, pembahasan hasil penelitian dan kesimpulan. Regresinya adalah :

\section{$Y=79,679-1,5356 \times$ (laki-laki) $Y=73,846-1,3906 X$ (perempuan)}

Penelitian dilakukan pada bulan OktoberDesember 2018 di Instalasi Radiologi Kedokteran Gigi Rumah Sakit Gigi dan Mulut Ladokgi TNI AL R.E. Martadinata Jakarta. Penelitian ini sudah mendapatkan persetujuan etik dari Komisi Etik Penelitian Universitas Padjadjaran Bandung dengan nomor 1161/UN6.KEP/EC/2018.

\section{HASIL}

Hasil penelitian ini diperoleh dengan metode Tooth Coronal Index (TCl) yaitu menghitung tinggi mahkota/Length of the Crown $(\mathrm{CL})$ dari Cemento Enamel Junction (CEJ) sampai ujung cusp tertinggi mahkota dan tinggi tanduk pulpa/Coronal Pulp Cavity Height yang diukur mulai dari Cemento Enamel Junction (CEJ) sampai ke ujung tanduk pulpa tertinggi pada arsip digital radiograf panoramik prajurit TNI AL. Karekteristik sampel berdasarkan usia dan jumlah dapat dilihat pada tabel 1.

\begin{tabular}{ccc} 
& Tabel 1. Karakteristik Sampel \\
\hline Usia & Laki-laki & Perempuan \\
\hline $20-25$ & 1 & - \\
$26-30$ & 17 & - \\
$31-35$ & 24 & - \\
$36-40$ & 33 & 1 \\
$41-45$ & 5 & - \\
$46-50$ & 4 & - \\
$51-55$ & 1 & - \\
\hline Total & 85 & 1 \\
\hline
\end{tabular}

Hasil penelitian menunjukkan bahwa terdapat 86 sampel yaitu usia 20-25 tahun terdapat 1 lakilaki, usia 26-30 tahun terdapat 17 laki-laki, usia 3135 tahun terdapat 24 laki-laki, usia 36-40 tahun

Tabel 2. Nilai rata-rata $\mathrm{CL}, \mathrm{CPCH}, \mathrm{TCl}$, regresi usia, usia dental

\begin{tabular}{lccccc}
\hline \multicolumn{1}{c}{ Variabel } & $\mathbf{n}$ & Minimum & Maximum & Mean & Std. Deviation \\
\hline $\mathrm{CL}$ & 86 & 7,0 & 11,0 & 8,9 & 0,9 \\
$\mathrm{CPCH}$ & 86 & 1,0 & 3,0 & 2,2 & 0,7 \\
$\mathrm{TCl}$ & 86 & 9,1 & 37,5 & 24,8 & 7,4 \\
Regresi Usia & 86 & 22,1 & 65,7 & 41,7 & 11,4 \\
Usia Dental & 86 & 22,1 & 65,7 & 41,7 & 11,4 \\
\hline
\end{tabular}


terdapat 33 laki-laki dan 1 perempuan, usia 41-50 tahun terdapat 9 laki-laki, dan usia 51-55 tahun terdapat 1 laki-laki.

Hasil rata-rata $\mathrm{CL} /$ Length of the Crown sebesar $8,9 \mathrm{~mm}$ dengan standar deviasi 0,9. Rata-rata $\mathrm{CPCH} /$ Coronal Pulp Cavity Height 2,2 mm dengan standar deviasi sebesar 0,7. Rata-rata pengukuran $\mathrm{TCl}$ adalah sebesar 24,8 dengan standar deviasi 7,4. Usia dental memiliki rata-rata 41,7 tahun dengan rentang minimum 22,1 tahun dan rentang paling tinggi 65,7 tahun. Hal ini tampak pada tabel 2 .

Uji perbandingan pada penelitian ini adalah dengan tujuan untuk membandingkan perbedaan rata-rata usia kronologis dan usia dental pada subjek yang diteliti dengan perhitungan Tooth Coronal Index (TCl). Namun sebelum dilakukan uji perbandingan, sebelumnya perlu menghitung normalitas data untuk menentukan jenis uj perbandingan yang akan digunakan apakah dengan uji parametris atau non parametris.

Uji normalitas digunakan untuk melihat apakah sebaran data berasal dari sebaran yang normal atau tidak. Selain itu uji normalitas berguna juga untuk menentukan jenis analisis yang tepat apakah menggunakan analisis parametris atau non parametris. Jika data tidak berdistribusi normal maka analisis menggunakan uji non parametris yaitu uji Wilcoxon, namun jika data berdistribusi normal maka analisis menggunakan uji parametris dengan menggunakan uji t berpasangan (paired $t$ test). Data dikatakan normal jika $p$ value $>0,05$, dan sebaliknya dikatakan tidka normal jika $p$ value < 0,05 .

Hasil uji normalitas usia kronologis dan usia dental pada 86 sebjek penelitian tampak pada tabel 3. Hasil uji normalitas didapat nilai $p$ value kurang dari 0,05 artinya data tidak memiliki distribusi normal. Data tidak memiliki distribusi data yang normal maka uji perbandingan menggunakan uji Wilcoxon t-test.

Hasil perhitungan tabel 4 menunjukkan uji perbandingan usia kronologis dan usia dental menggunakan indeks Tooth Coronal Index (TCl) menunjukkan nilai $p$-value sebesar 0,000 . Nilai $p$ value $(0,000)<0,05$ artinya terdapat perbedaan antara usia kronologis dengan usia dental menggunakan indeks Tooth Coronal Index (TCl) dengan rata-rata sebesar 41,7-35,4 $=6,3$. Artinya perbedaan rata-rata sebesar 6,3 tahun antara usia kronologis dengan usia dental dimana usia dental lebih tinggi dibandingkan dengan usia kronologis.

Hasil rata-rata usia dental kelompok usia berdasarkan hasil regresi dari rumus Tooth Coronal Index (TCl) yaitu : usia 20-25 mempunyai rata-rata usia dental sebesar 22,1 tahun dan rata-rata selisih usia kronologis dan usia dental adalah 1,9 tahun; usia 26-30 mempunyai rata-rata usia dental sebesar 40,69 tahun dan rata-rata selisih usia kronologis dengan usia dental adalah 11,75 tahun; usia 31-35 mempunyai rata-rata usia dental sebesar 39,34 dan rata-rata selisih usia kronologis dengan usia dental adalah 6,76 tahun; usia 36-40 mempunyai rata-rata usia dental sebesar 42 tahun dan rata-rata selisih usia kronologis dengan usia dental adalah 4,15 tahun; usia 41-45 mempunyai rata-rata usia dental sebesar 52,5 dan rata-rata selisih usia kronologis dengan usia dental adalah 8,7 tahun; usia 46-50 mempunyai rata-rata usia dental adalah 1,52 tahun; usia 51-55 mempunyai rata-rata usia dental sebesar 40,4 tahun dan rata-rata selisih usia kronologis dengan usia dental adalah 11,6 tahun. Data ini tampak pada tabel 5.

\begin{tabular}{ccccc}
\multicolumn{4}{c}{ Tabel 3. Uji normalitas } & \\
\hline & \multicolumn{3}{c}{ Shapiro-Wilk } & Keterangan \\
\cline { 2 - 4 } & Statistic & $n$ & $p$-value & \\
\hline Usia Kronologis & 0,970 & 86 & 0,042 & Tidak Normal \\
Usia Dental & 0,931 & 86 & 0,000 & Tidak Normal \\
\hline
\end{tabular}

Tabel 4. Uji perbandingan usia kronologis dan usia dental

\begin{tabular}{cccc}
\hline & Rerata \pm SD & p-value & Kesimpulan \\
\hline Usia Kronologis & $35,4 \pm 5,5$ & $0,000 *$ & terdapat perbedaan \\
Usia Dental & $41,7 \pm 11,4$ & & \\
\hline$\left.{ }^{*}\right)$ Wilcoxon t-test & & &
\end{tabular}

Tabel 5. Nilai rata-rata usia dental perkelompok usia

\begin{tabular}{ccc}
\hline Usia & Rata-rata usia dental & $\begin{array}{c}\text { Rata-rata selisih usia kronologis } \\
\text { dengan usia dental }\end{array}$ \\
\hline $20-25$ & 22.1 & 1.9 \\
$26-30$ & 40.69 & 11.75 \\
$31-35$ & 39.34 & 6.76 \\
$36-40$ & 42 & 4.15 \\
$41-45$ & 52.5 & 8.7 \\
$46-50$ & 48.77 & 1.52 \\
$51-55$ & 40.4 & 11.6 \\
\hline
\end{tabular}




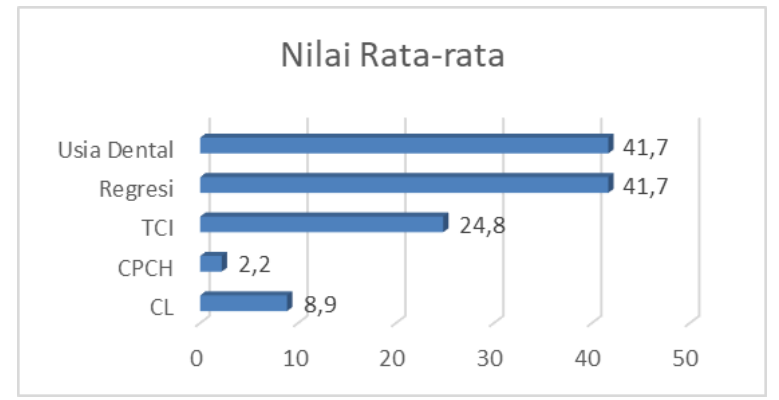

Gambar 3. Grafik rata-rata usia dental, $\mathrm{TCl}, \mathrm{CPCH}$ dan $\mathrm{CL}$

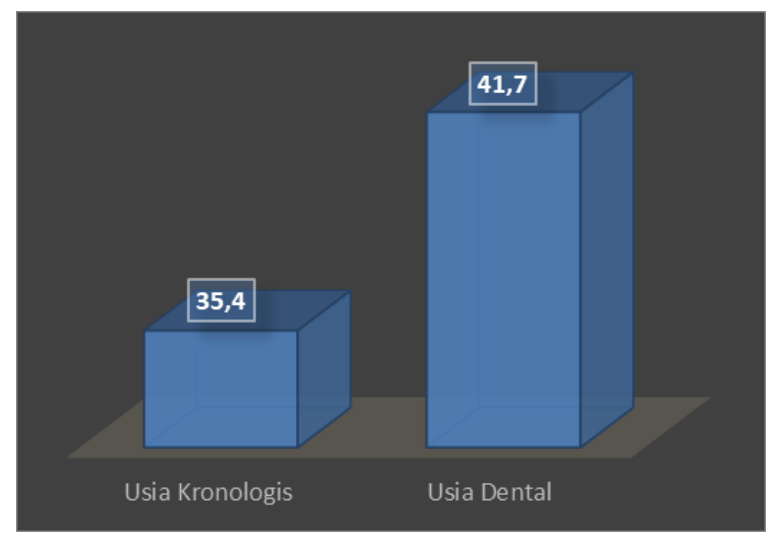

Gambar 4. Perbandingan usia kronologis dengan usia dental

Hasil rata-rata usia dental ditunjukkan pada gambar 3 dengan grafik. Hasil rata-rata usia dental dan regresi usia adalah 41,7 . Hasil rata-rata nilai Tooth Coronal Index (TCl) adalah 24,8. Hasil ratarata $\mathrm{CPCH} /$ Coronal Pulp Cavity Height adalah 2,2. Hasil rata-rata $\mathrm{CL} /$ Length of the Crown adalah 8,9.

Hasil rata-rata usia kronologis adalah 35,4 tahun. Hasil rata-rata usia dental adalah 41,7 tahun. Berdasarkan gambar 3 menunjukkan bahwa usia dental lebih tinggi dibandingkan dengan usia kronologis dengan selisih perbedaan 6,3 tahun.

\section{DISKUSI}

Penelitian ini menggunakan 86 sampel prajurit TNI AL yang mempunyai gigi molar pertama rahang bawah tanpa kelainan patologis pada arsip digital radiograf panoramik berdasarkan metode Tooth Coronal Index (TCI). Hasil penelitian ini didapatkan nilai usia dental lebih tinggi dibandingkan dengan usia kronologis. Hasil penelitian ini berbeda dengan penelitian dilakukan oleh Yulianti dkk tahun 2017 yang melakukan penelitian pada Suku Banjar menggunakan radiograf periapikal gigi premolar rahang bawah laki-laki dan perempuan. Hasil pada penelitian Yulianti dkk didapatkan nilai Tooth Coronal Index (TCI) dengan metode Benindra menunjukkan bahwa nilai Tooth Coronal Index (TCl) akan semakin menurun dengan meningkatnya usia. ${ }^{11}$ Penelitian lain juga dilakukan oleh Randjar et al, 2015 pada populasi Sulaimani di Iraq menggunkan radiograf panoramik gigi molar pertama rahang bawah laki-laki dan perempuan. Penelitain ini didapatkan nilai Tooth Coronal Index (TCl) semakin menurun dengan bertambahnya usia. ${ }^{12}$ Hal ini dapat disebabkan oleh suku dari prajurit yang heterogen sedangkan pada penelitianpenelitian sebelumnya menggunakan suku yang homogen. Populasi pada orang Indonesia mempunyai berbagai suku dan ras, salah satunya adalah ras Deutro-Melayu yang terdiri dari sukusuku Aceh, Melayu-Minangkabau, Lampung, Jawa, Sunda, Bali, Makassar, Bugis, Manado/Minahasa, dan Madura. Setiap orang dari berbagai suku termasuk prajurit TNI AL memiliki perbedaan ukuran rongga pulpa. Tugas sebagai prajurit mempunyai tingkat stress yang tinggi sehinga akan menyebabkan perubahan morfologi gigi seperti bruxism. Dampak dari bruxism ini dapat menyebabkan erosi yang dikaitkan dengan atrisi. Hal ini sejalan dengan pernyataan Harshanur, 1991 bahwa ukuran dari rongga pulpa dapat dipengaruhi oleh aktifitas fungsional seperti maloklusi, thermal shock, oklusi traumatis, abrasi, erosi, dan atrisi. Aktifitas fungsional dapat mempengaruhi pembentukan dentin sekunder, sehingga ukuran rongga pulpa setiap orang akan berbeda. Selain aktifitas fungsional, usia juga dapat mempengaruhi ukuran dari ruang pulpa. ${ }^{13}$ Ukuran ruang pulpa yang lebih banyak berkurang adalah bagian tanduk pulpa. Bagian tanduk pulpa yang lebih banyak berkurang adalah panjang tanduk pulpa dan ukuran tinggi kamar pulpa. Nutrisi dapat mempengaruhi perkembangan enamel dan dentin. Nutrisi yang dibutuhkan untuk perkembangan enamel dan dentin khususnya adalah vitamin A dan vitamin D. ${ }^{13}$ Prajurit yang bertugas selama bertugas di medan perang mungkin kurang mendapatkan asupan nutrisi yang baik termasuk vitamin sehingga akan mempengaruhi morfologi gigi. Selain itu, perbedaan pada penelitian ini bisa disebabkan oleh 
jumlah sampel yang sedikit, tidak ada pengelompokkan jenis kelamin, masa pakai pesawat sinar- $X$ yang kurang diperhatikan pemeliharaan dan perawatannya.

Godge P dkk, 2016 juga melakukan penelitian dengan metode Tooth Coronal Index (TCl) yang dilakukan pada populasi di India menggunakan radiograf panoramik gigi premolar kedua dan molar mandibula baik kanan dan kiri yang paling cocok untuk diukur pada laki-laki atau perempuan. Hasil pada penelitian Godge P dkk didapatkan rata-rata nilai Tooth Coronal Index (TCl) pada gigi premolar lebih tinggi daripada gigi molar. Penelitian pada prajurit TNI AL didapatkan nilai Tooth Coronal Index (TCl) gigi molar rahang pertama bawah lebih tinggi daripada usia kronologis. Hal ini mungkin disebabkan karena gigi premolar rahang bawah lebih terlihat daripada gigi molar dalam radiografi, selain itu ukuran keseluruhan rongga pulpa dan resolusi yang lebih rendah pada gigi molar dalam radiograf panoramik dimana batas atas rongga pulpa kadang-kadang kurang terlihat. ${ }^{14,15}$

Hasil pada penelitian ini didapatkan nilai Tooth Coronal Index $(\mathrm{TCl})$ gigi molar pertama rahang bawah lebih tinggi daripada usia kronologis yang sesuai dengan penelitian Badar SB dkk, 2016 dengan Tooth Coronal Index (TCl) pada sampel di Pakistan menggunakan radiograf panoramik gigi molar dan premolar rahang bawah laki-laki dan perempuan didapatkan hasil gigi molar menunjukkan nilai Tooth Coronal Index (TCl) yang lebih tinggi daripada gigi premolar. Hal ini dapat disebabkan oleh karena molar mandibula memiliki keanekaragaman morfologi daripada premolar dan disebabkan oleh variasi alami dalam deposisi dentin sekunder, ruang pulpa dan deposisi dentin sekunder diantara molar mandibula lebih baik divisualisasikan pada radiografi daripada premolar. ${ }^{16}$

Estimasi usia melalui radiograf dental dibutuhkan keterampilan dan ketepatan dalam pengukuran. Pengukuran kamar pulpa dipengaruhi oleh beberapa faktor penting seperti teknik radiografi, kualitas radiograf, dan interpretasi radiografik yang baik. Pemilihan dan prosedur teknik radiografi yang tepat dapat meminimalisasi distorsi yang terjadi, sehingga didapatkan keakuratan pengukuran lebih baik. Keterbatasan dalam penelitian ini dapat dilihat dari kualitas radiograf yang termasuk kejelasan dan ketepatan dimensi gambar juga dapat mempengaruhi interpretasi dan ketepatan pengukuran serta ketepatan gambaran struktur anatomi yang dapat ditampilkan pada suatu radiograf beserta dengan ketajaman dan visibilitas detil tiap gambaran struktur anatomi tersebut. ${ }^{17}$ Keterbatasan radiografi panoramik dalam mengestimasi usia, yaitu tidak dapat menghasilkan gambar anatomi yang jelas dan tajam seperti pada radiograf periapikal, permukaan proksimal gigi premolar biasanya saling tumpang tindih, distorsi, membutuhkan keakuratan dalam posisi pasien sehingga terhindar dari kesalahan posisi dan artefak. $^{3}$ keterbatasan lain dlam penelitian ini adalah mengenai software yang digunakan untuk pengukuran pada penelitian ini, karena pada software ini kurang sensitif dimana hasil angka yang didapatkan adalah bilangan bulat.

\section{SIMPULAN}

Berdasarkan penelitian ini dapat disimpulkan bahwa usia dental prajurit TNI AL berdasarkan Tooth Coronal Index (TCl) pada arsip digital radiograf panoramik lebih tinggi dibandingkan usia kronologis.

\section{DAFTAR PUSTAKA}

1. Peraturan Presiden Republik Indonesia Nomor 107 Tahun 2013 tentang Pelayanan Kesehatan Tertentu Berkaitan Dengan Kegiatan Operasional Kementerian Peratahanan, TNI, Kepolisian Negara Republik Indonesia. 2013. p.3.

2. White $S$, Pharoah $M$. Oral Radiology Principles and Interpretation. 7th ed. St. Louis, Missouri: Elsevier; 2014 p.166-168.

3. Nandiasa S, Kiswanjaya B, Yuniastuti M. 74 penggunaan radiograf gigi untuk kepentingan identifikasi forensik. 2016;3 p.74-77.

4. Yuniarti A, Zainal Arifin A, Yudhi Wijaya A, Nurul Khotimah W. An Age Estimation Method to Panoramic Radiographs from Indonesian Individuals. TELKOMNIKA (Telecommunication, Comput Electron Control. 2013;11(1): p.199.

5. Limdiwala $P$, Shah J. Age estimation by using dental radiographs. J Forensic Dent Sci. 2013;5(2): p.118.

6. Bashardoust N, Sheikhha M, Ardakani FE. The accuracy of dental panoramic radiography as an indicator of chronological age in Iranian individuals. J Forensic Odontostomatol. 2007;25 (2): p.30-35.

7. Asyraf AA. Estimasi Usia Berdasarkan Gambaran Gigi Radiografi Panoramik pada Metode Coronal Pulp Cavity Index (CPCI) di Kota Makassar [skripsi]. Universitas Hasanuddin. 2016: p.7-11.

8. Putri AS, Nehemia B. Perkiraan usia individu melalui pemeriksaan gigi untuk kepentingan forensik kedokteran gigi. 2013;62(3): p.55-63.

9. Chandramala R, Sharma R, Khan M, Srivastava A. Application of Kvaal 's Technique of Age Estimation on Digital Panoramic. 2012;2(6): p.6-10

10. Yulianti N, Irnamanda D, Fajar KD. Perbandingan Prakiraan Usia Dari Tooth Coronal Index. 2017;I(1): p.28-33.

11. RavleenThomas N, Supreet J, Priyanka A, Swati P, Sumit T, S NG. Tooth Coronal Index: Key for Age Estimation on Digital Panoramic radiographs. J Indian Acad Oral Med Radiol. 2018;30(1): p.64-67.

12. Harshanur. Anatomi Gigi. Jakarta. EGC; 1991: p.45

13. El Morsi DA, Rezk HM, Aziza A, El-Sherbiny M. Tooth Coronal Pulp Index as a Tool for Age Estimation in Egyptian Population. J Forensic Sci Criminol. 2015;3(2): p.1-8.

14. Godge $P$, Sharma S, Vibhakar P, Kulkarni S, Shroff J. Age Estimation Using Orthopantomographs-a Forensic Study: OctDec 2014. 2(4). p.26-30.

15. Badar SB, Ghafoor R, Khan FR, Hameed MH. Age estimation of a sample of Pakistani population using Coronal Pulp Cavity Index in molars and premolars on Orthopantomogram. J Pak Med Assoc. 2016: p.39-41.

16. Yang $F$, Jacobs R, Willems $G$. Dental age estimation through volume matching of teeth imaged by cone-beam CT. Forensic Sci Int. 2006;159(1): p.78-83.

17. Agitha SRA, Sylvia M, Utomo H. Estimasi Usia Anak Etnis Tionghoa di Indonesia dengan Mneggunakan Metode Willems. 2016: p.126

18. Yulianti N, Irnamanda D, Fajar KD. Perbandingan Prakiraan Usia Dari Tooth Coronal Index. 2017;191):28-33

19. El Morsi DA, rezk HM, Aziza A, El-Sherbiny M. Tooth Coronal Pulp Index as a Tool for Age Estimation in Egyptian Polpulation. J Forensic Sci Criminol. 2015;3(2):1-8 